\title{
El paisaje invisible de la arquitectura: una mirada sobre algunos paisajes andaluces
}

Santiago Quesada García, Dpto. Proyectos Arquitectónicos. Universidad de Sevilla

El paisaje de la arquitectura andaluza delata el modo en que su sociedad se ha ido adaptando a las diversas situaciones a lo largo del siglo XX
"Ante un determinado cuadro o página, nos preguntamos: ¿hasta qué punto es esto un paisaje? Pregunta que carecería de sentido si no creyésemos poseer una idea previa, un concepto-límite...", escribe Claudio Guillén cuando reflexiona sobre ese término de carácter ambiguo y polisémico. Y continúa: "...en el paisaje el hombre se vuelve invisible, pero no su mirada". Para realizar un enfoque que encuadre el paisaje construido por la arquitectura andaluza del pasado siglo y poder discernir sus formas es necesario definir, previamente, qué idea de paisaje estamos considerando, cuál es nuestra mirada.

Son la cultura, el acto cognoscitivo, la memoria, los que forman ese apunte previo. El paisaje es un fragmento de la realidad natural o artificial que los mecanismos de la percepción humana segregan por medio de la representación, de la proyección de la realidad como imagen. Sin embargo, la realidad es el producto de una actividad estructurante del sujeto, construida por medio de sus palabras a partir de la experiencia de los sentidos, por lo que el paisaje también es un momento del vasto proceso constitutivo de esa realidad. En palabras de Francisco Ayala, el paisaje significa y representa una realidad que es, a su vez, una inven- ción del hombre. Por un lado, significa a un objeto por medio de su imagen, otorgándole sentido mediante un conjunto de signos y, por otro, propone la representación de ese mismo objeto. Esta ambivalencia permite que el paisaje pueda ser entendido como un concepto en el que se supera la diferencia entre forma y contenido; como un límite en el que se sobreponen imagen y realidad. El paisaje se constituye en un lugar donde el espacio es objeto de experiencia y sujeto de deseo.

Somos memoria. La memoria produce intensas interferencias sobre el paisaje, tanto la memoria personal como la colectiva. La primera genera tantos paisajes como personas. La segunda es la memoria que cada sociedad ha desarrollado sobre su sentido de paisaje como un depósito de mitos, tradiciones e innovaciones que, como ocurre con el patrimonio, siempre está cambiando. Una memoria que establece la relación simbólica que une al sujeto con el medio natural que lo rodea y que le es transmitida de manera cultural. Un paisaje es cultura antes que visión de lo natural. Si el paisaje es la creación de una cultura, del conjunto de un pueblo, su continuidad, gestión e incremento es la consecuencia lógica de una comunidad que es 
(- Paraje de la Mella en Jaén, a la izquierda grupo de cien viviendas sociales (1958) / SANTIAGo QuESADA

capaz de sostenerse a sí misma. Su consideración como conjunto de bienes depende del marco histórico, social y cultural de esa sociedad. Esta dimensión es la que aporta al paisaje un sentido patrimonial.

En la actualidad, el paisaje se presenta lleno de autoridad y prestigio, no por una virtud particular sino porque representa y significa unas cualidades, perfectas e imperfectas, que en su totalidad simbolizan una armonía generalizable de valores éticos, estéticos, económicos, afectivos... Esa cualidad, concreta y universal a la vez, es la que provoca un deseo, incoativo y racional, de aprehender el paisaje por parte de los sujetos que lo experimentan. Ésa es la belleza del paisaje.

La anterior es una de las impresiones que aportan, a la retina o a la mente, algunas cualidades o factores que dibujan un boceto donde se comienza a percibir cierto paisaje como marco cultural de referencia. Va apareciendo un rico paisaje -algo desconocido, nada homogéneo y en constante mutación- del que surgen las obras de arquitectura producidas durante el pasado siglo en Andalucía. Edificios que componen un paisaje con diferentes intensidades y grados de coherencia pero que,

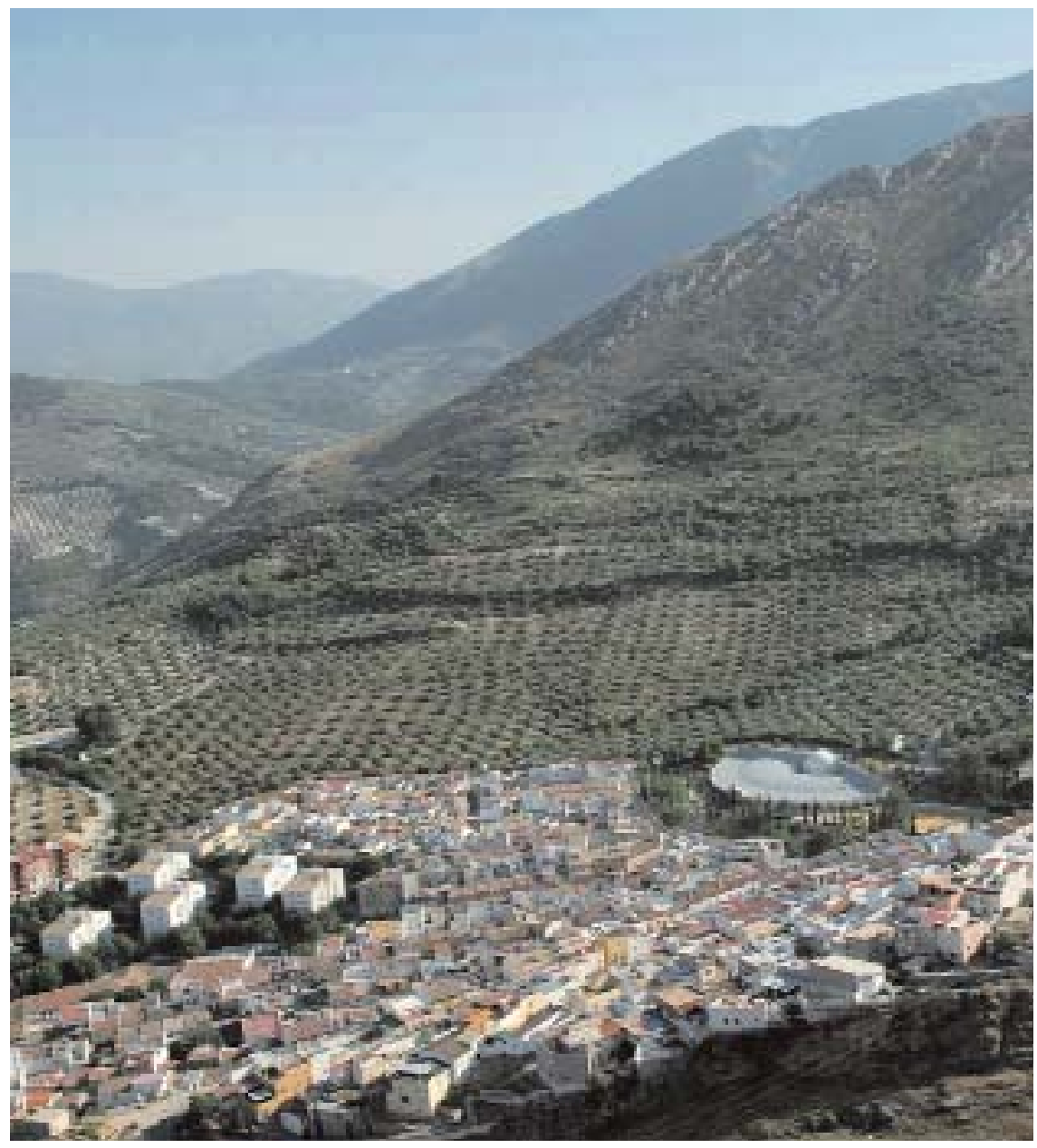




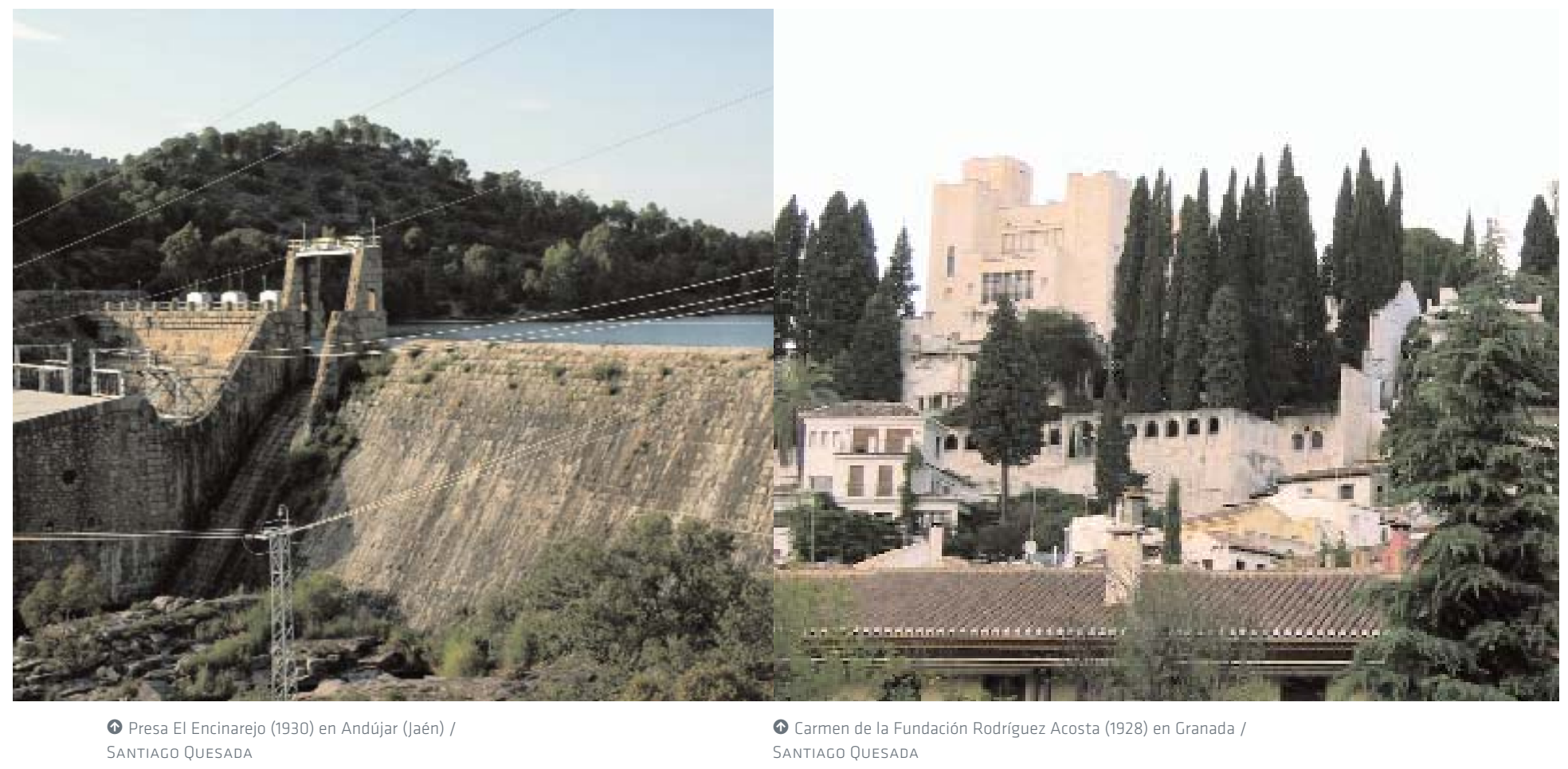

en su conjunto, definen un sistema estético con consistencia en un tiempo y una geografía determinados

El paisaje de la arquitectura andaluza delata el modo en que su sociedad se ha ido adaptando, a través de equilibrios más o menos frágiles, más o menos estables, más o menos adaptados, a las diversas situaciones que ha ido atravesando a lo largo del siglo veinte. Los elementos que componen ese paisaje, no necesariamente relacionados entre sí, han buscado su propia consistencia en las condiciones o circunstancias particulares de cada momento y cada lugar; como ocurre cuando diferentes fuerzas geológicas se concentran en un punto para formar una montaña o un volcán. Elevaciones que nunca surgen individualmente sino que siempre van precedidas o acompañadas de una compleja orografía que explica cómo y por qué surgió aquel elemento principal. De aquí surge la necesidad de reconocer, conocer y transmitir los estratos, montañas, bosques, ríos y valles que configuran la arquitectura andaluza, porque éstos son los que hacen posible que exista un terreno abonado del que surgen obras ejemplares. Es un paisaje que le otorga sentido, consistencia y rigor al proyecto contemporáneo de arquitectura.

Paisaje que comienza a formarse con las superficies, ricas en texturas, decoración e ingenio, de la Casa de la Peña en Almería o el Banco Central de Granada, edificios eclecticistas que tienen su continuación en los vistosos y coloridos tapices que son las fachadas de numerosos edificios regionalistas. El Gran Teatro Falla, la Facultad de Veterinaria de Córdoba o el Hotel Miramar en Málaga, tienen alzados que son taraceas desplegadas verticalmente hacia la calle, y que invitan a la mirada a detenerse, deambular, continuar... como ocurre en un jardín o en un paisaje.

Uno de los ríos que atraviesan este paisaje se encuentra embalsado con dos presas, el salto del Jándula y El Encinarejo. Ambas crean una nueva e inesperada sintaxis entre paisaje, industria y arquitectura. El paisaje no se entiende sólo como objeto, algo estático e 


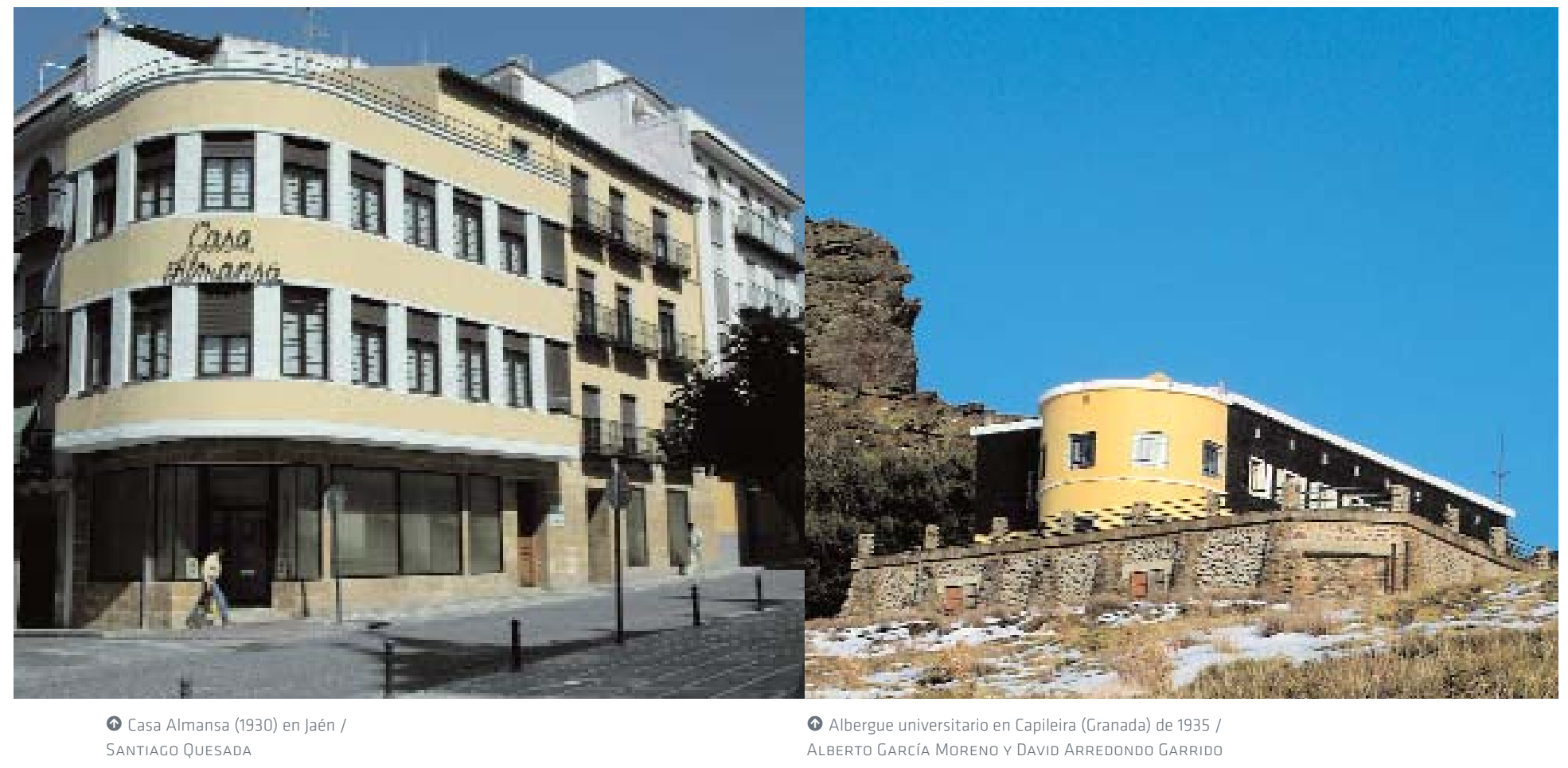

inmutable cuyo fin es ser contemplado y representado, sino como sujeto de experiencia que además puede ser construido. Los saltos y sus centrales eléctricas no se colocan como meros objetos funcionales dentro de un paisaje, sino que ellas mismas son paisaje. Un paisaje que se experimenta con plenitud cuando, con el zumbido constante de la central como fondo, se siente el agua rezumar entre unas piedras que parecen a punto de reventar de un momento a otro.

El ojo se mueve sin descanso buscando un lugar donde depositar la mirada. Durante ese incansable movimiento tienen lugar infinidad de paradas, sorpresas, ensoñaciones... La innovación que propone el carmen Rodríguez Acosta en Granada está relacionada con la ruptura del organicismo existente entre las calles y las casas del Realejo El nuevo carmen convierte el panorama cotidiano del barrio granadino en paisaje, insospechado hasta el momento de la construcción del proyecto de Anasagasti. El arquitecto altera los límites y propone, tanto desde el interior como del

exterior, una nueva apropiación sensorial de los elementos que existen en torno al edificio. La quinta con jardín invita a pasar, perderse, mirar a la deriva, encontrarse con la Alhambra, apropiarse de nuevas y sorprendentes vistas de la ciudad que, formando parte del jardín, se captan como parte de un paisaje no reconocido antes por las cerradas calles del Realejo.

Algunas culturas primitivas construían sus templos con forma de pirámide como eco de las montañas sagradas que tenían cercanas. John Ruskin también propuso, en algunos de sus dibujos, ciertas analogías entre montañas y arquitectura. Para él, el secreto de los montes residía en su movimiento incesante, en el pulso vital de las eras geológicas. La montaña está en continua transformación, tiende a erosionarse, como la arquitectura, cuyas ruinas parecen montículos de una cordillera recién formada. Cuando la arquitectura andaIuza comienza a incorporar, muy lentamente, los postulados del Movimiento Moderno tiene lugar la crisis de la metáfora mecanicista y, casi en paralelo, la contienda civil. Las huellas 
de la guerra marcan un nuevo paisaje caracterizado por unas ruinas en las que no es posible habitar.

Habitar se convierte en un problema y la vivienda en un objetivo prioritario, no sólo en España sino en Europa. Tras la guerra mundial, en 1947, se propone en los CIAM (Congresos Internacionales de Arquitectura Moderna) una arquitectura que satisfaga las necesidades emocionales del ser humano, que estimule su crecimiento espiritual. La mirada se desplaza hacia un panorama construido por la cultura popular, fruto de relaciones invariables entre hombre, arquitectura y medio. Junto a la virginidad moral del paisaje se redescubre al campesino y su tradición constructiva. Contra la abstracción hay una voluntad de realismo que encuentra en lo vernacular lo esencialmente humano.

Esperar lo inesperado es señal de un espíritu moderno, decía Oscar Wilde. En las ciudades, habitar significa construir y construir es el proceso de levantar una morada en un lugar donde es posible relacionarse con otras personas. En el paisaje andaluz, algunos arquitectos comienzan a pensar la ciudad desde y para la residencia. En ciertos casos se pone al individuo como centro de la organización del espacio habitable, como ocurre en los proyectos de la Barriada Huerta de Mena y La Esperanza en Huelva o en las Protegidas de Jaén. En otras ocasiones se proponen acertadas ordenaciones abiertas con bloques aislados, espacios libres arbolados y lenguajes cercanos al neorrealismo, como ocurre con el conjunto de las viviendas El Caracol en Córdoba, cuya disposición de bloques compone un inesperado e innovador espectáculo a la mirada contemporánea. Otra brillante ordenación abierta es el grupo de cien viviendas sociales en el barrio de San Felipe Neri de Jaén cuyos cinco bloques, con su particular sección, repiten cinco veces el perfil de la montaña que tienen detrás.

A mediados del siglo pasado se comienza a producir un proceso de radical mutación física y social en el paisaje, motivado por el desarro- llo económico y productivo, aunque en el campo todavía es posible reconocer una cierta autonomía figurativa unida a lo agrario. El paisaje labrado, fotografiado por Cartier-Bresson en España, es un mundo natural cultivado por la fatiga del hombre, independiente y libre de las aglomeraciones urbanas. Un paisaje que es rescrito, como en un palimpsesto, en torno a Atochares en Almería, Tahivilla en Cádiz, Maruanas en Córdoba, el Chaparral en Granada, Puente del Obispo en Jaén, la ampliación de Cártama en Málaga o Maribáñez en Sevilla, algunos de los trescientos nuevos poblados realizados por el Instituto Nacional de Colonización en Andalucía. Un laboratorio en el que arquitectos, ingenieros y agrónomos diseñaron, durante tres décadas, una nueva materialidad sobre el territorio heredado, reescribiendo su red de caminos, infraestructuras, parcelaciones, caminos, cultivos, edificios y poblados. Construyendo, en definitiva, un nuevo paisaje.

El cruce de fuerzas capaz de generar objetos se concentra, a partir de la década de los sesenta, a lo largo de la costa andaluza y en una actividad concreta. El acontecimiento del turismo produjo situaciones que generaron arquitecturas de una innegable calidad. El Hotel Alay en Benalmádena, Los Lebreros en Sevilla, el Centro turístico en Punta Mona de Almuñécar, son edificios prismáticos o estructuras cristalográficas que parecen reflejar la forma geométrica de la roca sobre la que se asientan. Aspectos del proceso de regeneración de la montaña de la arquitectura, fragmentos de un paisaje en continua transformación que varía sólo con girar la mirada hacia otro punto. En otro lugar y otro tiempo, encontramos que la cristalización de los minerales se encuentra en fase más avanzada, los agentes naturales los han tallado y pulido como si fueran una escultura.

El edificio de viviendas en la calle Da María Coronel en Sevilla es como una piedra horadada por la acción del mar o del viento que se ha ido introduciendo en su interior a través de un estrecho canal de acceso. El espacio resultan- 
(- Hotel Los Lebreros (1973) en Sevilla / SAntIAGo QueSADA

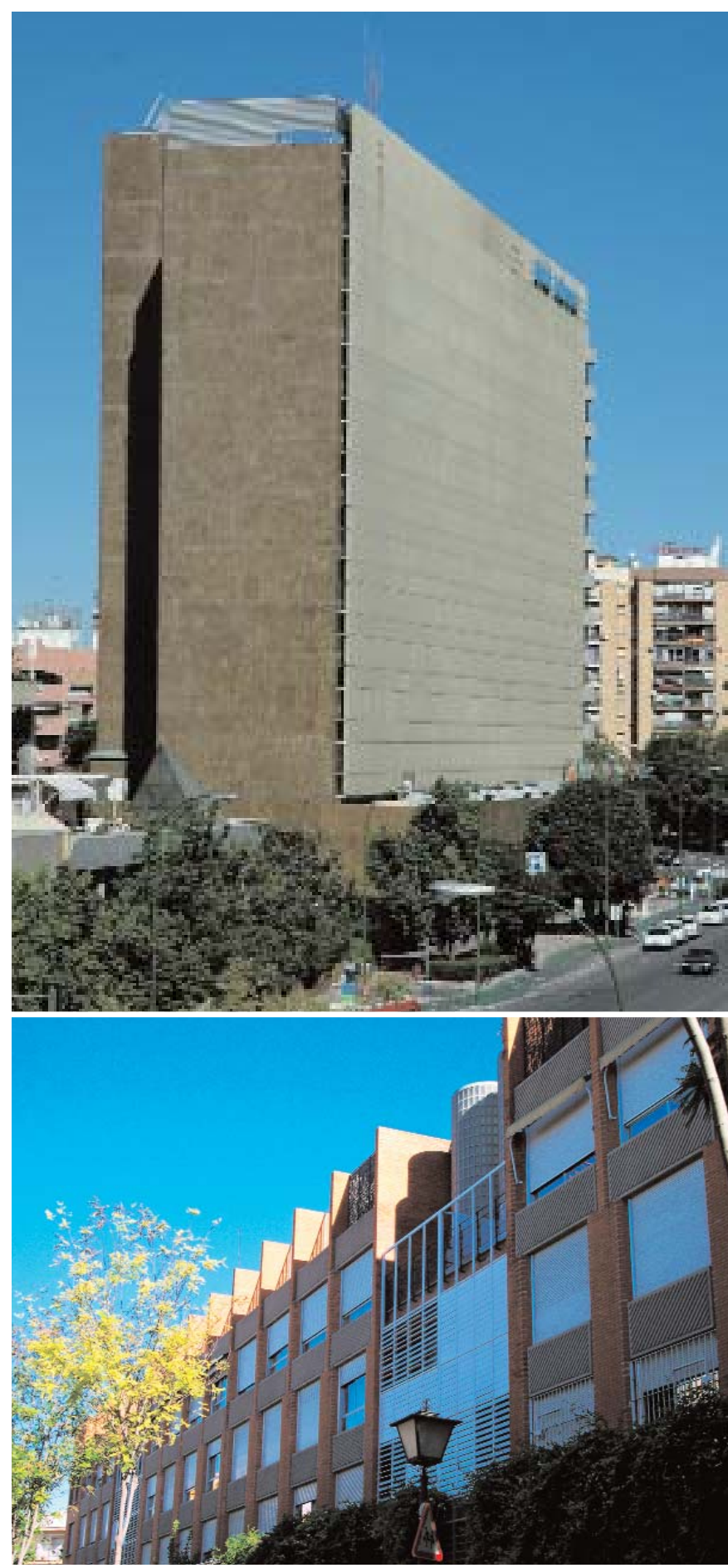

(1) Manzana de viviendas en El Porvenir (Sevilla), obra realizada en 1979 / amadeo Ramos Carranza
( Edificio Compañía Sevillana de electricidad en Sevilla (1968) / IÑAKI SÁnCHEZ-CID ENDÉRIZ
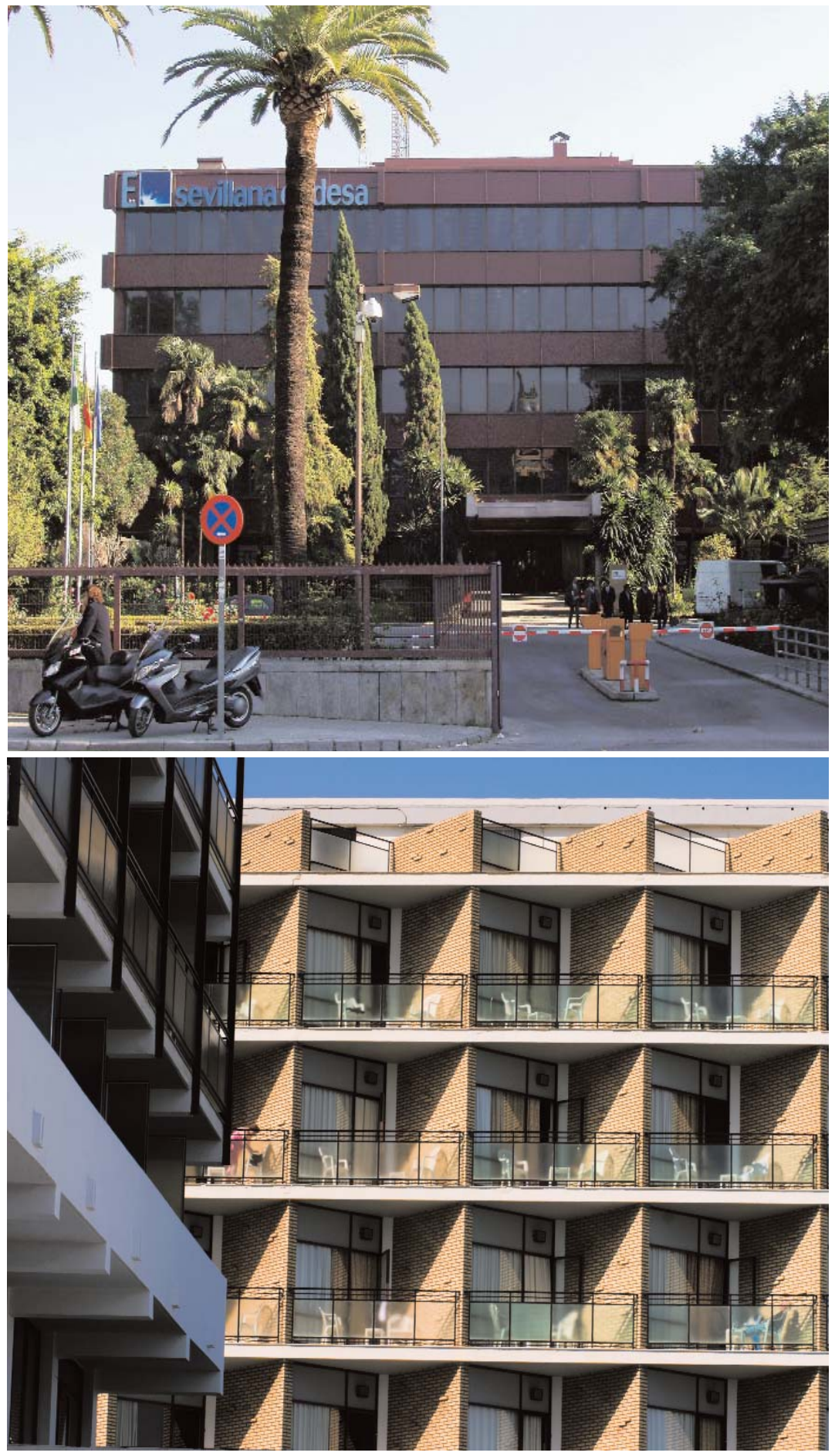

(1) Hotel Alay en Benalmádena (Málaga), de 1964

Iuan Carlos CAzalla, IAPH 


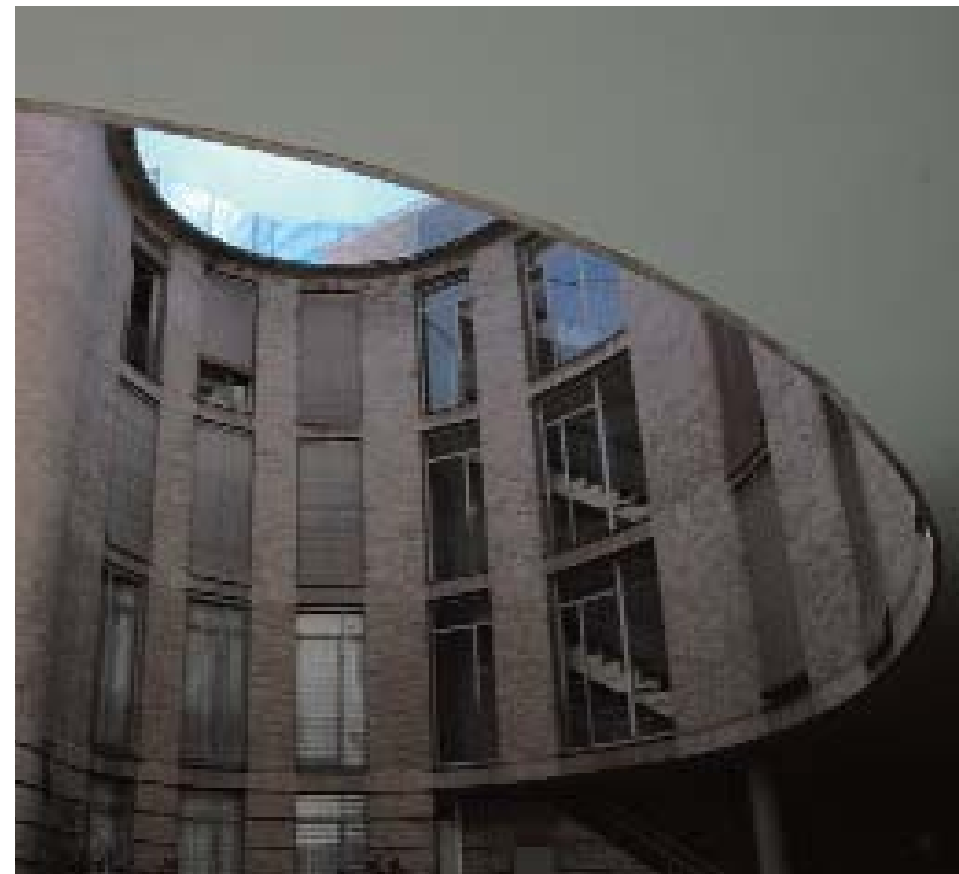

(1) Viviendas en calle Doña María Coronel (1976) Sevilla / SAntiago Quesada

te, con una importante dosis de movimiento genera multitud de puntos de vista donde la sorpresa y la variedad son las constantes. Un Iugar plástico y maleable que tensiona al máximo la manera de percibir lo interno y lo externo. Un interior que sólo produce el exterior del edificio como revés, ambigüedad característica de cualquier paisaje.

En esta fugaz y somera visión de algunos paisajes, la mirada se detiene en un cubo sin atributos. Un prisma que se ha desprendido de todos los elementos sobre los que la mirada ha deambulado, girado, depositado, a lo largo de la arquitectura del siglo veinte. La mirada se inmoviliza frente a una blanca y elemental forma cúbica. La Casa Gaspar en Zahara, en vez de causarnos el recuerdo del pasado, nos provoca el olvido del futuro. Desencaja el lugar donde se exhibe como una obra minimalista, desmenuza la articulación del tiempo e impide la experiencia más allá de las fotografías. Esta casa confirma que el paisaje es un límite donde se sobreponen imagen y realidad. La visión moderna

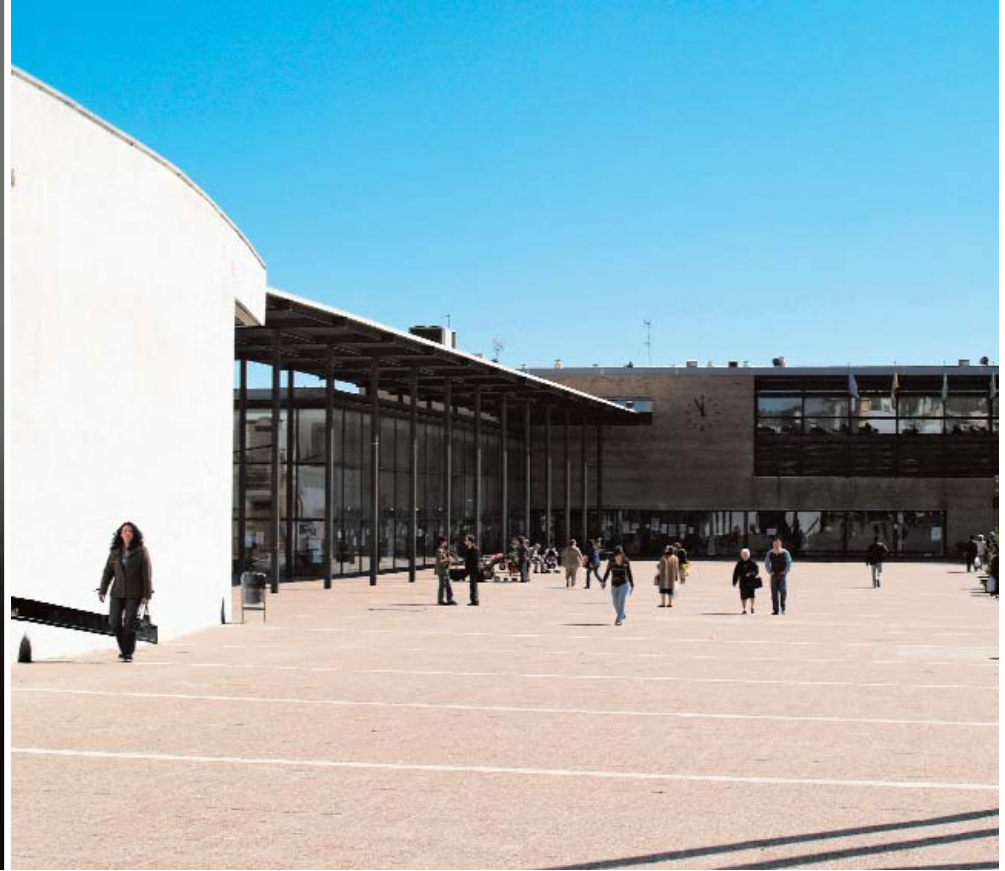

(1) Biblioteca y Ayuntamiento (1992) en Camas (Sevilla) / IGnacio CAPILLA Roncero se ha caracterizado por una construcción exterior, indirecta y sobre todo mediática. Lo real y lo virtual ya no tienen el antiguo significado metafísico. El medio y la experiencia son dos caras de la misma moneda. El paisaje y la arquitectura son, a la vez, el resultado y el medio.

La sobremodernidad conduce a constantes desplazamientos de la mirada y recreaciones de imágenes. Para el individuo contemporáneo la captura de nuevos paisajes ha convertido el viaje en un instrumento fundamental donde las imágenes recurrentes son siempre las de un atlas. El viajero necesita hacer un mapa, un itinerario, organizar un conjunto de conocimientos, cada vez más fragmentados, en una lista especializada y voluntariamente no ideológica. Ese viaje remite a la responsabilidad personal de trazar un recorrido posible, disponer los materiales de lo contemporáneo en una narración que pueda ser compartida por los demás. Éste es uno de los sentidos de conocer los paisajes andaluces de la arquitectura. 